\title{
Brotes de rabia humana transmitida por vampiros en los municipios de Bajo y Alto Baudó, departamento del Chocó, Colombia 2004-2005
}

\author{
Jessika Valderrama ${ }^{1}$, Ingrid García ${ }^{1}$, Germán Figueroa ${ }^{2}$, Edilberto Rico ${ }^{3}$, Juliana Sanabria ${ }^{2}$, \\ Nicolás Rocha ${ }^{2}$, Edgar Parra ${ }^{4}$, Cecilia Saad ${ }^{5}$, Andrés Páez ${ }^{6,7^{*}}$ \\ ${ }^{1}$ Subdirección de Vigilancia y Control en Salud Pública, Instituto Nacional de Salud, Bogotá D.C., Colombia. \\ ${ }^{2}$ Secretaría de Salud del Departamento del Chocó, Chocó, Colombia. \\ ${ }^{3}$ Dirección Nacional de Zoonosis, Ministerio de la Protección Social, Bogotá D.C, Colombia. \\ ${ }^{4}$ Laboratorio de Patología, Instituto Nacional de Salud, Bogotá D.C., Colombia. \\ ${ }^{5}$ Subdirección de Epidemiología, Instituto Nacional de Salud, Bogotá D.C., Colombia. \\ ${ }^{6}$ Laboratorio de Virología, Instituto Nacional de Salud, Bogotá D.C., Colombia. \\ ${ }^{7}$ Departamento de Ciencias Básicas, Universidad de La Salle, Bogotá D.C., Colombia. \\ Este estudio se realizó en el Instituto Nacional de Salud, Bogotá, D.C., Colombia.
}

Introducción. Entre mayo y julio de 2004 ocurrió en la comunidad Embera de Birrinchao de cuenca del río Purricha, Bajo Baudó, Chocó un brote de rabia humana con 14 víctimas. En enero de 2005 otro brote similar ocurrió en las comunidades negras de Pató y Nauca, Alto Baudó, Chocó, con tres nuevas víctimas.

Objetivos. Describir los brotes de rabia humana transmitida por vampiros de mayor magnitud hasta ahora reportados en Colombia. Describir las técnicas diagnósticas utilizadas y las acciones de control de foco aplicadas. Discutir sobre el significado epidemiológico de estos brotes y sus implicaciones en salud pública.

Materiales y métodos. Los casos se diagnosticaron por inmunofluorescencia directa, prueba biológica en ratones e inmunohistoquímica. Los virus se tipificaron por inmunofluorescencia indirecta utilizando anticuerpos monoclonales. Las acciones de control de foco en Bajo Baudó consistieron en un censo poblacional, aplicación de vacuna y tratamientos antirrábicos a los pobladores, vacunación canina y felina y aplicación de anticoagulante a murciélagos.

Resultados. Cuatro casos humanos fueron confirmados positivos para rabia de ambos brotes. Otros 13 se dedujeron por nexos epidemiológicos. La variante antigénica 3 fue caracterizada en dichos casos. Se llevaron a cabo acciones en Bajo Baudó diseñadas para el control de foco de rabia humana transmitida por vampiros.

Conclusiones. El brote de rabia humana en Bajo Baudó 2004 ha sido el de mayor magnitud reportado en Colombia. Este fue causado por vampiros, demostrando la amenaza que representa la rabia de especies silvestres para la salud pública, y la necesidad de implementar acciones para evitar su impacto en humanos. Se desconoce si existen vínculos entre este brote y el reportado en Alto Baudó seis meses después.

Palabras clave: virus de la rabia, Lyssavirus, quirópteros, vínculo humano-animal, zoonosis, brotes de enfermedades, Colombia

Outbreaks of human rabies transmitted by vampire bats in Alto Baudó and Bajo Baudó municipalities, department of Chocó, Colombia, 2004-2005

Introduction. During months May to July 2004, a rabies outbreak in the Embera community of Birrinchao, in the Purricha river basin department of Chocó was reported with 14 human deaths. Another rabies outbreak was reported in January 2005 in the black communities of Pató and Nauca in the neighboring municipality of Alto Baudó with 3 human deaths.

Objectives. To describe the largest outbreaks of human rabies transmitted by vampire bats reported in Colombia to date. To describe the diagnostic laboratory techniques used, and the activities undertaken for the control of rabies in the area. To discuss the epidemiologic 
significance and public health implications of these rabies outbreaks.

Materials and methods. Rabies diagnosis was achieved by direct immunofluorescence, inoculation of mice and immunohistochemistry. Typing of the virus was achieved by indirect immunofluorescence using monoclonal antibodies. Rabies control activities were undertaken in Bajo Baudó consisting in a population census, human vaccination and application of antirabies sera, vaccination of dogs and cats, and application of anticoagulant to bats.

Results. Four human cases were confirmed as positive for rabies in both rabies outbreaks. Another 13 rabies cases in humans were inferred by strong epidemiological links. Rabies antigenic variant 3 was identified in the samples studied. Rabies control activities were conducted for a human rabies outbreak caused by vampire bats.

Conclusions. The human rabies outbreak in Bajo Baudó has been the largest reported in Colombia. It was caused by vampire bats, showing that these animals are a threat for human health. The implementation of control strategies for this kind of epizootic outbreaks is needed in South America. It remains unknown whether there is a link between this outbreak and one reported 6 months later in the neighboring municipality of Alto Baudó.

Key words: rabies virus, Lyssavirus, chiroptera, bonding, human-pet, zoonoses, disease outbreaks, Colombia.

La rabia es una zoonosis causada por virus neurotrópicos del género Lyssavirus, familia Rhabdoviridae, orden Mononegavirales. El virión rábico contiene ARN de cadena sencilla y sentido negativo no segmentado, y codifica cinco proteínas estructurales (1). La rabia es una enfermedad terminal principalmente de animales; en humanos es un reflejo del grado de contacto con animales infectados. La infección con virus rábicos ocurre en dos formas epidemiológicas diferentes: a) la rabia urbana, con el perro como principal reservorio y transmisor de la enfermedad a los humanos, y b) la rabia silvestre con especies depredadoras como los felinos y animales como el zorro, el vampiro, el chacal y otros que actúan como reservorios y transmisores principalmente a especies herbívoras. Eventualmente ocurre la transmisión de la rabia entre los dos ciclos epidemiológicos (2-9), lo que resalta el riesgo que la enfermedad en cualquier especie animal presenta para los humanos. De las 1.000 especies de murciélagos registradas en el mundo (10), sólo tres se alimentan de sangre de vertebrados $(11,12)$ y habitan exclusivamente en América Latina (13). Desmodus rotundus es el más

\footnotetext{
Correspondencia:

Andrés Páez Martínez, Laboratorio de Virología, Instituto Nacional de Salud,

Av. El Dorado Cra 50 CAN, Bogota D.C, Colombia.

Telefax: 57-1-2200928. apaezm@ins.gov.co
}

Recibido: 29/09/05; aceptado: 28/07/06 ampliamente distribuido en la zona y se alimenta de sangre de vertebrados, aunque esporádicamente de aves (13). Las otras dos especies son Diaemus youngi y Diphylla ecaudata, las cuales son muy escasas y usualmente se alimentan de sangre de aves (12). Todos los reportes de brotes de rabia en humanos causada por vampiros han sido relacionados exclusivamente con $D$. rotundus. En los meses de mayo a julio de 2004 se confirmó la aparición de un brote de rabia transmitida por vampiros en indígenas Embera de la comunidad de Birrinchao en la rivera del río Purricha, municipio de Bajo Baudó, departamento de Chocó (figura 1) con un registro de 14 personas muertas (14). En enero de 2005 ocurrió otro brote similar, aparentemente de menor magnitud, que registró tres víctimas adicionales en las comunidades negras de Pató y Nauca, municipio de Alto Baudó (15). En total se reportaron 17 personas muertas por rabia en ambos brotes según los datos oficiales del Ministerio de la Protección Social de Colombia $(14,15)$ (cuadro 1). En el presente artículo se describen en detalle los mencionados brotes, las técnicas diagnósticas utilizadas, los procedimientos para la tipificación viral y las acciones de control de foco y prevención llevadas a cabo en la cuenca del río Purricha del municipio de Bajo Baudó en los meses posteriores al brote. En el municipio de Alto Baudó las acciones de control de foco y prevención no se llevaron a cabo debido a múltiples factores, entre los que se cuentan el difícil acceso a la zona y los problemas de orden público. 

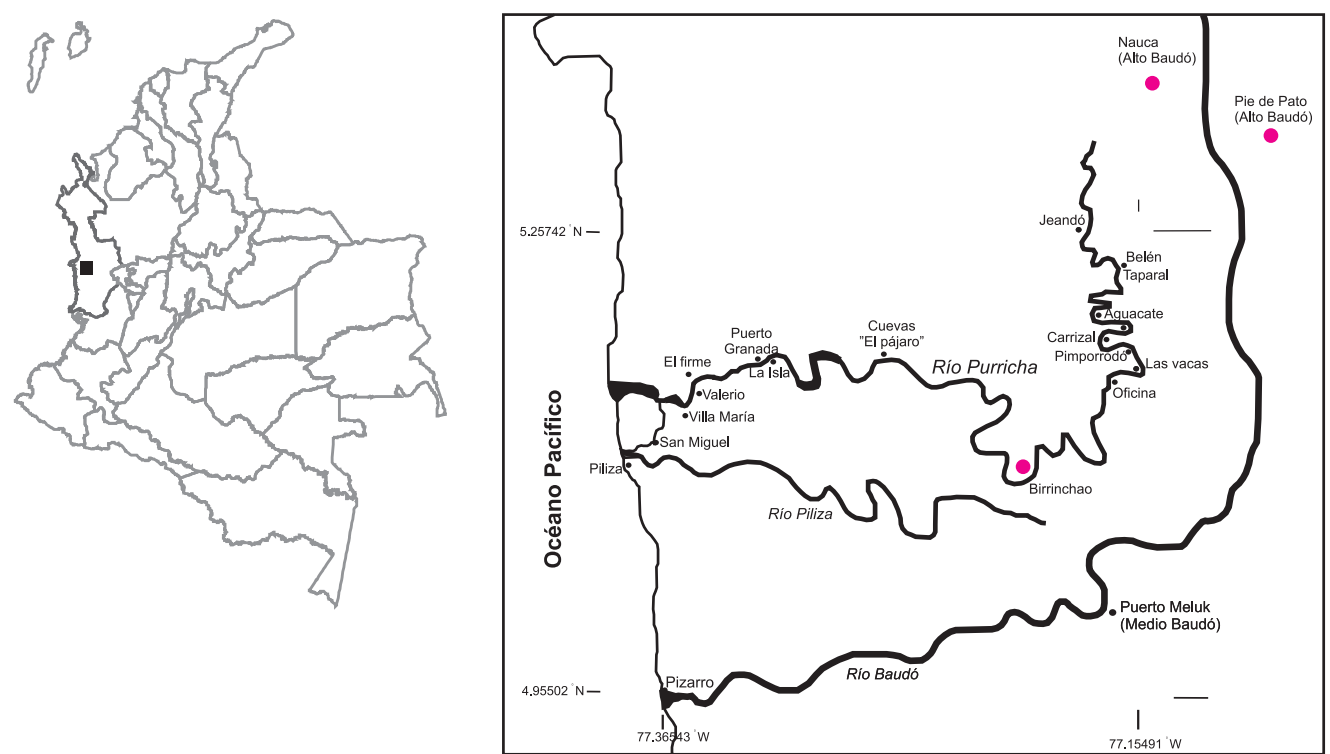

Figura 1. Localización geográfica de la zona de los brotes de rabia humana, Bajo y Alto Baudó, departamento de Chocó, Colombia, 2004-2005. Mapa que muestra la localización geográfica de la cuenca de los ríos Purricha y Baudó, departamento del Chocó, Colombia, 2004-2005. En las comunidades marcadas con rojo ocurrieron los casos de rabia humana. La localización de la zona en Colombia se muestra en la parte superior izquierda de la figura.

\section{Materiales y métodos}

\section{Descripción geográfica de la zona y de la comunidad}

Las coordenadas geográficas del área se obtuvieron por medio del dispositivo de Geoposicionamiento Global GPS MAGELLAN 315, con el cual se hizo un mapa de la zona afectada. Se realizó un censo de población en las comunidades indígenas de Pizarro, Villamaría, Birrinchao y otras ubicadas en la cuenca del río Purricha, así como en las comunidades afrocolombianas de Valerio y Villamaría y otras de la mencionada cuenca. El censo se realizó casa por casa con una encuesta que contenía las variables edad, sexo, procedencia, exposición a mordeduras de murciélago y localización de la mordedura.

\section{Descripción de los casos de rabia}

En las comunidades visitadas se indagó por la presencia de casos probables de rabia actuales o anteriores, de los cuales se realizó la descripción clínica correspondiente complementada con la información del centro de salud y los sitios de remisión de pacientes y muestras. Para la descripción de cada caso se tuvieron en cuenta los contactos familiares del paciente, la edad, el sexo, la ubicación anatómica y el grado de la exposición rábica, las fechas de inicio de síntomas y muerte.

\section{Diagnostico y tipificación antigénica del virus de la rabia}

El diagnóstico de los casos de rabia se realizó en los Laboratorios de Virología y Patología del Instituto Nacional de Salud en Bogotá. Las técnicas utilizadas fueron las de inmunofluorescencia directa sobre material encefálico fresco (16), en la cual anticuerpos policlonales antirrábicos marcados con fluoresceína reconocen antígeno viral presente en dicho material y se produce señal visible al microscopio de fluorescencia. Adicionalmente se emplearon las técnicas de histopatología convencional e inmunohistoquímica utilizando avidina-biotina conjugada con peroxidasa sobre material encefálico en fijado en formol neutro al 10\%; el anticuerpo primario policlonal se empleó con dilución 1:160 (17). La prueba confirmatoria se hizo por inoculación en 
Cuadro 1. Casos de rabia humana en el departamento de Chocó, Colombia, 2004-2005.

\begin{tabular}{|c|c|c|c|c|c|}
\hline Caso & Sexo & Edad & Inicio de síntomas & Muerte & Diferencia en días \\
\hline 1 & $\mathrm{~F}$ & 8 & 03/05/04 & $13 / 05 / 04$ & 10 \\
\hline 2 & M & 8 & $11 / 05 / 04$ & $13 / 05 / 04$ & 2 \\
\hline 3 & $\mathrm{M}$ & 8 & $13 / 05 / 04$ & 18/05/04 & 5 \\
\hline 4 & M & 4 & $11 / 05 / 04$ & $18 / 05 / 04$ & 7 \\
\hline 5 & M & 12 & $13 / 05 / 04$ & $20 / 05 / 04$ & 7 \\
\hline 6 & $\mathrm{~F}$ & 8 & $18 / 05 / 04$ & $24 / 05 / 04$ & 6 \\
\hline 7 & M & 6 & $28 / 05 / 04$ & $01 / 06 / 04$ & 5 \\
\hline $8^{a}$ & M & 9 & 29/05/04 & 07/06/04 & 10 \\
\hline 9 & $M$ & 6 & 07/06/04 & $11 / 06 / 04$ & 4 \\
\hline 10 & $\mathrm{~F}$ & 9 & 07/06/04 & $12 / 06 / 04$ & 5 \\
\hline $11^{\mathrm{a}, \mathrm{b}}$ & $M$ & 6 & $18 / 06 / 04$ & $22 / 06 / 04$ & 4 \\
\hline 12 & $\mathrm{~F}$ & 3 & $18 / 06 / 04$ & $25 / 06 / 04$ & 7 \\
\hline 13 & M & 5 & $22 / 04 / 06$ & $27 / 06 / 04$ & 5 \\
\hline 14 & $\mathrm{~F}$ & 7 & 09/07/04 & $19 / 07 / 04$ & 10 \\
\hline 15 & M & 12 & $13 / 01 / 05$ & $21 / 01 / 05$ & 8 \\
\hline $16^{\mathrm{a}, \mathrm{b}}$ & $M$ & 14 & $16 / 01 / 05$ & $27 / 01 / 05$ & 11 \\
\hline $17^{\mathrm{a}, \mathrm{b}}$ & $F$ & 13 & $25 / 01 / 05$ & $07 / 02 / 05$ & 13 \\
\hline
\end{tabular}

${ }^{a}$ Casos confirmados por el laboratorio.

${ }^{\text {b } V \text { ariante antigénica } 3 .}$

ratones de laboratorio de una suspensión de material encefálico tomado de las personas sospechosas de haber tenido infección rábica. La inoculación fue intracerebral en ratones de laboratorio cepa Institute of Cancer Research (ICR) (18). La tipificación antigénica del virus se realizó por inmunofluorescencia indirecta utilizando material encefálico infectado con los virus rábicos de cada caso, un panel de ocho anticuerpos monoclonales producidos en ratón del Centers for Disease Control and Prevention (CDC) en Atlanta USA (19), y un anticuerpo secundario IgG antiratón producido en cabra conjugado con fluoresceína (SIGMA 065H-8874). El patrón general de reactividad (reacción positiva o negativa) de los ocho anticuerpos monoclonales en conjunto arrojó como resultado la variante antigénica de los virus aislados en cada uno de los casos.

\section{Vacunación}

Se dividió la cuenca del río Purricha en dos zonas: a) Alto Purricha (Birrinchao, Oficina, Las Vacas, Pimporrodo, Carrizal, Aguacate, Belén Taparal y Jeandó), correspondiente a las comunidades indígenas, y b) Bajo Purricha (Villa Maria, Valerio, San Miguel, Punta Purricha Terrón, Puerto Granada, Playa Nueva, El Firme, La Isla y Cantil), correspondiente a las comunidades afrocolombianas. La red de frío para el almacenaje de las vacunas se garantizó con el uso de neveras, cajas térmicas y plantas eléctricas. Los aborígenes fueron informados por medio de un traductor sobre la razón y el objetivo de los procedimientos que se les iban a practicar. Por dificultades de comunicación no fue posible obtener consentimiento informado escrito de cada uno de ellos, sin embargo no hubo rechazo alguno a la intervención médica. Se realizó una prueba de sensibilidad inicial a las personas vacunadas. Para el tratamiento pre-exposición se aplicó una dosis de la vacuna Ravipur (Chiron) los días 0, 7 y 28 a toda persona habitante de los municipios arriba mencionados sin antecedentes de mordedura por murciélago hematófago u otro animal transmisor en 2004. Para el tratamiento pos-exposición se aplicó a toda persona con antecedente de mordedura por murciélago $u$ otro animal transmisor de rabia durante el 2004, y a toda persona en contacto con secreciones tales como saliva, lágrimas y en general contacto con mucosas de un paciente con rabia. El tratamiento pos-exposición consistió en la aplicación del suero Favirab (Aventis Pasteur) o el suero fabricado por el Instituto Nacional de Salud. La dosis de los mencionados sueros fue de $40 \mathrm{UI}$ por $\mathrm{kg}$. de peso. Además del suero, se aplicaron cinco dosis (doble en el día 0 , y en los días 7,14 y 28) intramusculares deltoideas de vacuna antirrábica 
(Ravipur-Chiron en la comunidad de Birrinchao y Rabivac-Brilliant Industries en el resto de la población de la cuenca).

\section{Control de transmisores y reservorios}

Se capturaron murciélagos en la comunidad de Birrinchao por medio de mallas. A los especimenes capturados se les aplicó en el dorso el anticoagulante difenadiona. Se realizó vacunación canina y felina inicialmente en la cuenca del río Purricha y posteriormente en todo el municipio. La vacunación de estos animales consistió en una dosis única de Rabican producida por la Empresa Colombiana de Productos Veterinarios, Vecol S.A.

\section{Análisis estadístico de la información}

Se creó una base de datos en Office Excel XP para llevar el registro del proceso de vacunación de cada paciente en tiempo real. El análisis de los datos se realizó en EPI-INFO versión 3.3.2, realizando análisis univariado y divariado y usando razones, proporciones y las pruebas estadísticas básicas.

\section{Resultados}

\section{Descripción geográfica de la cuenca del río Purricha}

Las comunidades expuestas al brote de rabia de los meses de mayo a julio de 2004 habitan en la zona ribereña del rió Purricha, municipio de Bajo Baudó (figura 1), en una zona selvática de difícil acceso ubicada al occidente de Colombia en el departamento del Chocó, con una humedad relativa del $95 \%$ y presencia de poblaciones de murciélagos. La población estimada es de 2.491 personas, de las cuales el $33 \%$ es indígena de la etnia Embera, mientras que la población en el municipio de Alto Baudó es de raza negra en su mayoría. La economía es de autosubsistencia basada en la agricultura y la recolección de plátano y maíz. Los animales que conviven con las comunidades son perros y ocasionalmente gallinas y cerdos, algunos de los cuales presentaron mordeduras de vampiro y murieron durante los meses de mayo y junio de acuerdo con testimonios de la comunidad. Las viviendas de las comunidades negras e indígenas son de madera en su mayoría, con techos altos de paja, conocidas como tambos. Las personas duermen en el suelo, y con toldillos sólo en algunos casos como única medida de protección contra la mordedura de murciélagos. La atención en salud que recibe la población se hace por medio de brigadas de salud semestrales provenientes del municipio de Pizarro.

\section{Censo poblacional en la cuenca del río Purricha}

El número de habitantes en las poblaciones censadas se muestra en el cuadro 2 , y la distribución por edad de la comunidad, en el cuadro 3. La población con antecedentes de mordedura por murciélago en el último año en la comunidad del Bajo Baudó correspondió a 25,2\%. El grupo de 10 a 14 años de edad fue el que comparativamente presentó el mayor número de personas mordidas, con $36,8 \%$, seguido del grupo de cinco a ocho años con 34,6\%. Existe un mayor riesgo de mordedura de murciélago en el grupo de las personas menores de 15 años de edad (RP 1,71 IC 95\% 1,44 a 2,03; $p<0,005)$. Los sitios de mordedura reportados con mayor frecuencia fueron cara y cabeza, con $53 \%$, seguido de mordeduras en rodilla o pierna con $32 \%$. En Birrinchao se censaron 228 personas. El total de la población

Cuadro 2. Número de habitantes en las poblaciones censadas de la comunidad de la cuenca del río Purricha, municipio de Bajo Baudó, julio de 2004.

\begin{tabular}{lc}
\hline Población & Habitantes \\
\hline Aguacate & 148 \\
Birrinchao & 228 \\
Cantil & 107 \\
Carrizal & 35 \\
El Firme & 43 \\
Jeandó & 23 \\
La Isla & 39 \\
Las Vacas & 93 \\
Oficina & 51 \\
Punta Granada & 69 \\
Punta Nueva & 103 \\
Punta Purricha & 58 \\
Pimporrodó & 71 \\
Punta Catripe & 23 \\
San Miguel & 87 \\
Taparal & 182 \\
Terrón & 387 \\
Valerio & 105 \\
Villa María & 152 \\
Total & 2004 \\
\hline
\end{tabular}


Cuadro 3. Distribución por edades de la comunidad de la cuenca del río Purricha, municipio de Bajo Baudó, julio de 2004.

\begin{tabular}{lcr}
\hline Grupo por edades & Personas & \multicolumn{1}{c}{$\%$} \\
\hline Menor de 5 & 433 & $20,80 \%$ \\
5 a 9 & 432 & $21,70 \%$ \\
10 a 14 & 326 & $16,40 \%$ \\
15 a 19 & 118 & $6,00 \%$ \\
20 a 29 & 231 & $11,60 \%$ \\
30 a 39 & 188 & $9,50 \%$ \\
40 a 49 & 110 & $5,50 \%$ \\
Mayor de 50 & 166 & $8,40 \%$ \\
Total & $\mathbf{2 0 0 4}$ & $\mathbf{1 0 0 , 0 0 \%}$ \\
\hline
\end{tabular}

es indígena, siendo la mediana de edad 12 años. El $59,2 \%$ es menor de 15 años y el $50,4 \%$ es de sexo femenino. La proporción de población con antecedentes de mordedura de murciélago fue de $52,6 \%$. El mayor porcentaje de personas mordidas se reportó en el grupo de cinco a nueve años con $76,5 \%$, seguido del grupo de 10 a 14 años con $67,4 \%$. La cabeza y la cara son los sitios de mordedura más frecuentes con $62,7 \%$, seguidos de las extremidades superiores con $22,7 \%$ y las inferiore con $14,5 \%$. El $80 \%$ de las mordeduras por murciélago en niños menores de cinco años ocurrió en cara y cabeza, porcentaje que en los niños entre 10 y 14 años descendió a 78\%. En contraste, las personas mayores de 15 años refirieron ser mordidas en mayor proporción (42\%) en las extremidades superiores. En Bajo Purricha, 606 personas eran mujeres $(51,6 \%)$ y $567(48,4 \%)$, hombres. El $85,1 \%$ de los pobladores tenía antecedentes de mordedura de murciélago, del cual el $42,5 \%$ fue en la cabeza, el $50,8 \%$ en el pie y el 3,9\% en la mano. En Alto Purricha, 444 personas eran mujeres $(53,4 \%)$ y 387 , hombres $(46,65 \%)$. El 60,6\% tenía antecedentes de mordedura por murciélago, del cual $55,6 \%$ ocurrió en la cabeza, $19,7 \%$ en el pie, $18,8 \%$ en la mano, $2,2 \%$ en el codo y $0,6 \%$ en la cara.

\section{Descripción de los casos}

El primer caso de rabia en la cuenca del río Purricha fue detectado por una brigada médica proveniente del Centro de Salud del municipio de Pizarro el 20 de mayo de 2004. Este caso correspondía a un menor de sexo masculino que presentaba un cuadro clínico de cuatro días de evolución con cefalea, fiebre, malestar general y dificultad respiratoria. Se inició el manejo de su cuadro febril y de su sintomatología respiratoria. Después de dos días sin respuesta positiva al tratamiento de primera línea para paludismo, hidratación con líquidos endovenosos e inhalaciones de salbutamol, el paciente empeoró y murió. Posteriormente se realizó un registro de pacientes con sintomatología similar. El número registrado de muertes fue de 17 según datos oficiales del Ministerio de la Protección Social de Colombia $(14,15)$. De éstas, 14 ocurrieron en la comunidad de Birrinchao, Bajo Baudó (cuadro 1, casos 1 al 14), en los meses de mayo, junio y julio de 2004, y tres en el mes de enero de 2005 en el Alto Baudó, dos en el municipio de Pie de Pató (cuadro 1, casos 15 y 16) y uno en Nauca (cuadro 1, caso 17); se desconoce si fue un resurgimiento del brote ocurrido en Bajo Baudó o si, por el contrario, fue un acontecimiento aislado (cuadro 1). No existían antecedentes de vacunación antirrábica en ninguna de las dos comunidades en el momento de los brotes. En la cuenca del río Purricha en Bajo Baudó, la tasa de mortalidad fue de 0,7 por cien habitantes. La tasa de mortalidad en la comunidad de Birrinchao fue de 6,1 por cien habitantes; es de señalar que el total de los casos de rabia procedía de esta comunidad. Del total de casos, el $64,3 \%$ correspondía a niños con edades entre los 3 y los 12 años; la mediana de edad fue de 7,5 años. El tiempo transcurrido entre el inicio de los síntomas y la muerte de los casos ocurrió entre los 2 y los diez días con una mediana de 5,5 días. La totalidad de los casos tenía antecedentes de múltiples mordeduras.

\section{Diagnóstico y tipificación antigénica del virus}

Fue imposible confirmar la totalidad de los casos debido a dificultades para la exhumación de cadáveres y la negativa de los familiares a que se practicaran autopsias. Se confirmó la infección por virus rábicos únicamente en los pacientes de los casos 8, 11, 16 y 17 (cuadro 1), en los cuales se detectó la presencia de antígeno rábico por inmunofluorescencia y un grave proceso inflamatorio linfomonocitario, con manguitos perivasculares y perdida neuronal. Este hallazgo se visualizó en el segmento medular de $\mathrm{C} 1$ y en bulbo,observaciones que corresponden a mielitis 
grave de predominio en el tallo. Se observaron pequeñas inclusiones intra-citoplasmáticas de tipo Negri (H\&E 100X) en neuronas del asta de Ammon (20). En el cerebelo y en la corteza cerebral se identificaron antígenos virales rábicos por técnicas de inmunohistoquímica con anticuerpos policlonales. Se aisló la variante antigénica 3 , típica de rabia transmitida por murciélago hematófago, -como la única variante presente en el material encefálico de los casos 11, 16 y 17 (cuadro 1).

\section{Vacunación}

En la cuenca del río Purricha en Bajo Baudó, se realizó inicialmente la vacunación de 219 indígenas de la comunidad de Birrinchao que se encontraban desplazados en diferentes zonas a lo largo de la ribera del río en las poblaciones de Birrinchao, Villamaría y Pizarro. El $72,4 \%$ de éstos, correspondiente a 157 personas, finalizó satisfactoriamente el esquema. Posteriormente, teniendo en cuenta la división realizada de la zona y los resultados obtenidos del censo, se vacunó la población con los siguientes resultados: en Alto Purricha, 820 personas iniciaron el esquema de vacunación antirrábica, de las cuales 328 (40\%) recibieron el esquema pos-exposición, y 486 $(60 \%)$, el esquema pre-exposición. Con las 820 personas vacunadas, la cobertura general de vacunación obtenida fue de $77,2 \%$. La población con mayor porcentaje de cobertura fue Pimporrodó con $97,2 \%$ y la de más baja cobertura fue Belén de Taparal con $54,9 \%$. De los pacientes con mordedura por murciélago, 295 (correspondiente a $90 \%$ ) recibieron el esquema pos-exposición con el cual se inmunizó a las personas a los 0, 3, 7 y 11 días. En el esquema pre-exposición se inmunizó a las personas en los días 0, 7 y 26 . En Bajo Purricha, la población que inició el esquema de vacunación fue de 1.173 personas, de las cuales $181(15,4 \%)$ recibieron el esquema posexposición, y 992 (74,5\%), el esquema preexposición. Con las 1.173 personas vacunadas, la cobertura general de vacunación obtenida fue de $86 \%$. La comunidad con mayor porcentaje de cobertura fue San Miguel con $100 \%$ y la de menor cobertura fue Valerio con $47,6 \%$. Ciento trece pacientes expuestos a rabia recibieron inmunización, cifra que corresponde al $62 \%$ del total de expuestos. El esquema de vacunación antirrábica pos-exposición promedio contempló inmunizaciones a los $0,3,7,14$ y 45 días. $\mathrm{El}$ esquema pre-exposición incluyó inmunizaciones a los 0,7 y 45 días. No se presentó ninguna reacción de sensibilidad positiva al suero, ni complicaciones en su aplicación.

\section{Control de transmisores y reservorios}

La vacunación canina y felina en la cuenca del río Purricha, municipio de Bajo Baudó, comenzó en Birrinchao donde se vacunaron ocho animales, y en el resto de la cuenca se inmunizó a 198 perros y 11 gatos. En total se vacunaron 775 perros y 55 gatos en el resto del municipio, lo cual corresponde a una cobertura aproximada de 60\% en perros y $40 \%$ en gatos. Se capturaron 105 murciélagos en la comunidad de Birrinchao. A los especimenes capturados se les aplicó en el dorso el anticoagulante difenadiona. De los animales capturados, $70 \%$ se caracterizó como hematófago y $30 \%$ como de otras especies, principalmente frugívoros, lo cual refleja la relación existente entre el número de murciélagos hematófagos y no hematófagos en la zona.

\section{Discusión}

La infección por virus de rabia ha sido ampliamente reportada en murciélagos hematófagos y no hematófagos. Los primeros han sido relacionados con brotes de la enfermedad en humanos y animales domésticos, principalmente bovinos, mientras que los segundos han sido responsables únicamente de casos aislados de rabia en humanos. La transmisión de la rabia de murciélagos hematófagos a humanos ha sido reportada durante los últimos 80 años en nueve países de Latinoamérica (Trinidad, Guyana, México, Brasil, Bolivia, Argentina, Surinam, Belize, Perú y Colombia) (21-26). El brote de rabia transmitida por murciélagos hematófagos a humanos en la comunidad de Birrinchao, cuenca del río Purricha, municipio de Bajo Baudó, descrito en el presente artículo es el primero de gran magnitud reportado en Colombia. Existen, sin embargo, evidencias indirectas de casos aislados de rabia transmitida por quirópteros a caninos y humanos en Colombia (27). Se desconoce si dicho brote tuvo vínculos 
con el brote reportado en enero de 2005 en las comunidades de Pató y Nauca del municipio aledaño de Alto Baudó, en el cual se reportaron tres muertes humanas. En este estudio los brotes se consideraron como eventos separados teniendo en cuenta las distancias geográficas y temporales entre ellos. Aunque la confirmación de la presencia de virus de la rabia sólo se logró en 4 de las 17 personas muertas en ambos brotes, las autoridades sanitarias dedujeron la presencia de infección rábica en las 13 personas restantes con base en estrechos nexos epidemiológicos $(14,15)$. Los criterios para establecer que la causa de muerte había sido la rabia en los 13 casos no confirmados incluyen el hecho de que estas personas eran vecinas y familiares de las personas confirmadas como positivas para rabia; que la sintomatología y el cuadro clínico fueron compatibles con infección rábica, hecho que nunca antes se había observado en la zona según testimonios recogidos en la comunidad, y que todas presentaban antecedentes de mordeduras por murciélago hematófago. Adicionalmente, el lapso de tiempo entre la aparición de los síntomas y la muerte resultó ser muy similar (cuadro 1). Tan pronto se confirmaron los primeros casos de rabia en la cuenca del río Purricha, municipio de Bajo Baudó, en el mes de mayo de 2004, se planearon las acciones de control de foco descritas en este artículo, las cuales implicaron la formación y desplazamiento de un equipo de profesionales de la salud a la zona, y consistieron en un censo poblacional, vacunación humana y animal y aplicación de anticoagulante a murciélagos. En contraste, ninguna de estas actividades se realizó durante o después del brote de rabia reportado en las comunidades de Pató y Nauca aledañas al municipio de Alto Baudó en enero de 2005 debido a factores tales como la dificultad de acceso a la zona y los problemas de orden público. Los resultados de la tipificación viral por medio de anticuerpos monoclonales en tres de los casos de ambos brotes demostraron que los virus pertenecían a la variante antigénica 3 , la cual está asociada a murciélagos hematófagos. No fue posible practicar el examen de tipificación viral a la primera muestra debido a que se sumergió en formol antes de ser enviada a nuestro laboratorio. Los resultados de tipificación viral y los informes epidemiológicos anteriores sobre ausencia de variantes antigénicas diferentes a la variante 3 , así como la ausencia de rabia canina en la zona, sugieren que los brotes objeto de este estudio fueron causados en su totalidad por virus cuyo reservorio son las murciélagos hematófagos. En este grupo, los más frecuentemente asociados con rabia son los pertenecientes a la especie $D$. rotundus, los cuales se encuentran distribuidos desde el norte de México hasta el cono sur y en las islas de Trinidad y Margarita en el Océano Atlántico en altitudes de hasta 3.500 metros sobre el nivel del mar. Las otras dos especies de murciélagos hematófagos corresponden a Diaemus youngi y Diphylla ecaudata (28). La recolección de información entre los habitantes de la cuenca del río Purricha en Bajo Baudó evidenció la alta tasa de mordeduras de murciélagos hematófagos en los pobladores. Históricamente se ha considerado a los perros como los principales reservorios y transmisores del virus de la rabia a humanos; sin embargo, los datos presentados en nuestro estudio indican que estos animales no tuvieron relevancia epidemiológica en los brotes estudiados. Aun así, tanto perros como gatos fueron incluidos en las estrategias de control de foco con el fin de prevenir su contagio con virus rábicos. En este respecto, aunque es poco probable la agresión de un murciélago hematófago a un perro o gato, sí es muy factible lo contrario, o sea la agresión de éstos a murciélagos rabiosos que generalmente caen al suelo sin poder volar. En el mes de marzo de 2004, es decir dos meses antes del brote de rabia en la cuenca del río Purricha reportado en este artículo, se reportó en el estado de Pará en Brasil un brote de rabia en humanos en el cual murieron 22 personas, en su mayoría menores de edad (29). En los estudios posteriores al brote se conoció que la variante antigénica 3 se aisló en las víctimas, indicando que el brote fue causado por murciélagos hematófagos. Un hecho común en los brotes de rabia reportados en Brasil y Colombia y en otros en Latinoamérica es que las víctimas son menores de edad. No se ha determinado si los murciélagos hematófagos prefieren alimentarse de sangre de personas jóvenes. Sin embargo, este fenómeno se puede explicar por la inmunidad adquirida contra la rabia 
por las personas adultas que han tenido exposiciones al virus frecuentemente a lo largo de su vida. Los menores de edad carecen de dicha inmunidad por haber tenido menor número de exposiciones al virus (30). Los brotes de rabia reportados en el presente estudio, así como otros brotes similares en Latinoamérica, evidencian claramente la gran amenaza que la rabia silvestre representa para la salud humana, en especial la transmitida por vampiros, en momentos en que la rabia canina está siendo controlada de manera efectiva por vacunación en Colombia y en otros países de la zona. Desde 1997, la rabia canina en Colombia ha estado restringida casi en su totalidad a los departamentos de la Costa Atlántica, en donde se ha logrado disminuir significativamente la casuística mediante intensos programas de vacunación en caninos. Hasta octubre de 2005 se habían reportado únicamente dos casos de rabia asociada a perro en dicha región y en Colombia (Laboratorio de Virología, Instituto Nacional de Salud, Bogotá D.C., Colombia).

\section{Agradecimientos}

Los autores del presente estudio desean agradecer la inmensa colaboración de Arturo Díaz Gómez y del Instituto Colombiano Agropecuario (ICA) en las fases de tipificación viral y geoposicionamiento de la zona de estudio.

\section{Conflicto de intereses}

Los autores declaramos que no existe ningún tipo de interés que pueda influir en los resultados de este artículo.

\section{Financiacion}

Los recursos económicos necesarios para el trabajo de campo y de laboratorio fueron aportados por el Ministerio de la Protección Social y el Instituto Nacional de Salud de Colombia.

\section{Referencias}

1. Wunner WH, Larson JK, Dietzschold B, Smith CL. The molecular biology of rabies virus. Rev Infect Dis 1988;10(Suppl. 4):771-84.

2. Bourhy H, Kissi B, Audry L, Smreczak M, Sadkowska-Todys M, Kulonen K, et al. Ecology and evolution of rabies virus in Europe. J Gen Virol 1999;80:2545-57.
3. Guerra MA, Curns AT, Rupprecht CE, Hanlon CA, Krebs JW, Childs JE. Skunk and raccoon rabies in the eastern United States: temporal and spatial analysis. Emerg Infect Dis 2003;9:1143-50.

4. Nel LH, Jacobs J, Jaftha J, Meredith C. Natural spillover of a distinctly Canidae-associated biotype of rabies virus into an expanded wildlife host range in southern Africa. Virus Genes 1997;15:79-82.

5. Sabeta CT, Bingham J, Nel LH. Molecular epidemiology of canid rabies in Zimbabwe and South Africa. Virus Res 2003,91:203-11.

6. Johnson N, Black C, Smith JS, Un H, McElhinney LM, Aylan O, et al. Rabies emergence among foxes in Turkey. J Wildl Dis 2003;39:262-70.

7. Krebs JW, Williams SM, Smith JS, Rupprecht CE, Childs JE. Rabies among infrequently reported mammalian carnivores in United States, 1960-2000. J Wildl Dis 2003;39:253-61.

8. Stankov S. Typing of field rabies virus strains in FR Yugoslavia by limited sequence analysis and monoclonal antibodies. Med Pregl 2001;54:446-52.

9. Páez A, Saad C, Núñez C, Bóshell J. Molecular epidemiology of rabies in northern Colombia 1994-2003: evidence for human and fox rabies associated with dogs. Epidemiol Infect 2005;133:529-36.

10. Findley JS. Bats: a community perspective. Cambridge: Cambridge University Press; 1995.

11. Gardner A. Feeding habits. In: Baker RJ, Jones-Jr JK, Carter DC, editors. Biology of bats of the New World. Family Phyllostomatidae. Part II. Lubbock, Texas: Texas Tech Press; 1977.

12. Greenhall AM. Feeding behavior. In: Greenhall AM, Schmidt U, editors. Natural history of vampire bats. Florida: CRC Press; 1988.p.111-31.

13. Koopman KF. Systematic and distribution. In: Greenhall AM, Schmidt U, editors. Natural history of vampire bats. Florida: CRC Press; 1988.p.7-17.

14. Ministerio de la Protección Social. Resolución 2103 julio 1 de 2004. Rabia humana transmitida por murciélagos hematófagos en Bajo Baudó. Bogotá D.C., Colombia, 2004.

15. Ministerio de la Protección Social. Resolución 000201 febrero 8 de 2005. Rabia humana transmitida por murciélagos hematófagos en Alto Baudó. Bogotá D.C., Colombia, 2004

16. McQueen JL, Lewis AL, Schneider NJ. Rabies diagnosis by fluorescent antibody. I. Its evaluation in a public health laboratory. Am J Public Health 1960;50:1743-52.

17. Rodríguez G. Diagnóstico inmunológico del virus de la rabia en tejido incluido en parafina. Inf Quinc Epidemiol Nac 1997;16:235-6. 
18. Koprowski H. Prueba de inoculación en ratones. En: Organización Mundial de la Salud. Técnicas de Laboratorio aplicadas a la rabia. Washington D.C.: OPS/ OMS; 1956.p.57-69.

19.Dietzschold B, Rupprecht CE, Tollis M, Lafon M, Mattel J, Wiktor TJ, et al. Antigenic diversity of the glycoprotein and nucleocapsid proteins of rabies and rabies related viruses: implications for epidemiology and control of rabies. Rev Infect Dis 1988;10(Suppl. 4):785-98.

20. Parra EA, Neira M, Roa D. Rabia humana por virus tipo 3 Bajo Baudó, Chocó. Biomédica 2004;24:237-8.

21. Baer GM. Vampire bat and bovine paralytic rabies. In: Baer GM, editor. The Natural History of Rabies. $2^{\text {nd }}$ edition. Boston: CRC Press: 1991. Cap. 20.

22. Fundação Nacional da Saúde. Morcegos em áreas urbanas e rurais: Manual de Manejo e Controle. Brasilia: Ministério da Saúde; 1996.

23. Lopez A, Miranda PP, Tejada E, Fishbein DB. Outbreak of human rabies in the Peruvian jungle. Lancet 1992;339:408-12.

24. Gonçalves MA, Sa-Neto RJ, Brazil TK. Outbreak of aggressions and transmission of rabies in human beings by vampire bats in northeastern Brazil. Rev Soc Bras Med Trop 2002;35:461-4.
25. Schneider MC, Santos-Burgoa C. Algunas consideraciones sobre la rabia humana transmitida por murciélagos. Salud Publica Mex 1995;37:354-62.

26. Suescún O. Rabia en Antioquia, 1988. Boletín Epidemiológico de Antioquia 1988;14:62-5.

27. Páez A, Núñez C, García C, Bóshell J. Molecular epidemiology of rabies epizootics in Colombia: evidence for human and dog rabies associated with bats. J Gen Virol 2003;84:795-802.

28. Greenhall A. Etología y ecología de los murciélagos vampiros. Reunión de consulta sobre la atención de personas expuestas a rabia transmitida por vampiros. Washington D.C.: Organización Panamericana de la Salud/Organización Mundial de la Salud; 1991;p.11-8.

29. Ministry of Health of Brazil. Department of Health Surveillance. Human rabies transmitted by bats in Pará State, Brazil, 2004. Tecnical Note 16 April. Sao Paulo: Ministry of Health of Brazil, Department of Health Surveillance; 2004.

30. Orr PH, Rubin MR, Aoki FY. Naturally acquired serum rabies neutralizing antibody in a Canadian Inuit population. Arctic Med Res 1988;47(Suppl. 1):699-700. 